\title{
Two approaches to a new heterocyclic system of pyrazolo[4,3-e][1,2,4]triazolo[1,5-c]pyrimidine
}

\author{
Valery V. Mezheritsky, ${ }^{a}$ Vladimir I. Minkin, ${ }^{a}$ Lyudmila G. Minyaeva, ${ }^{a}$ \\ Roman G. Tyurin, ${ }^{a}$ Valery V. Krasnikov, ${ }^{a}$ Eugeny V. Vorobyev, ${ }^{a}$ and Zoya A. Starikova* ${ }^{b}$ \\ ${ }^{a}$ Institute of Physical and Organic Chemistry Rostov State University, \\ 194/2, Stachka Av. Rostov on Don, 344090, Russia \\ E-mail: mezher@ipoc.rsu.ru \\ ${ }^{b}$ A. N. Nesmeyanov Institute of Organoelement Compounds of Russian Academy of Science \\ E-mail:star@xray.ineos.ac.ru
}

\section{Dedicated to Prof. Alexander T. Balaban on the occasion of his $75^{\text {th }}$ Birthday in recognition of his outstanding contributions to theoretical chemistry and chemistry of heterocyclic compounds}

(received 26 May 04; accepted 13 Aug 04; published on the web 10 Dec 04)

\begin{abstract}
Derivatives of a new heterocyclic system, viz. pyrazolo[4,3-e][1,2,4]triazolo[1,5-c]pyrimidine 5, have been synthesized by coupling imidoesters of 1-substituted-5-aminocarbonitriles 2 with acylhydrazides. The thermal recyclization of 1-substituted-4-(2-acylhydrazin-1-yl)pyrazolo[3,4$d]$-pyrimidines $\mathbf{7}$ is found to be an alternative approach to the heterocyclic system 5.
\end{abstract}

Keywords: 2,7-Disubstituted pyrazolo[4,3-e][1,2,4]triazolo[1,5-c]pyrimidines, bis-heterocyclization, carboxylic acids hydrazides

\section{Introduction}

The imidoesters 2 obtained by coupling 5-amino-1H-pyrazole-4-carbonitriles $\mathbf{1}$ with triethyl orthoformate react with amines to form a heterocyclic pyrazolo[3,4- $d$ ]pyrimidine system, ${ }^{1,2}$ the compounds of which display interesting chemical properties ${ }^{1-6}$ and possess a wide spectrum of biological activities. ${ }^{7-11}$ We have presumed that by employing hydrazides as the amine components of this reaction, the cascade heterocyclization $\mathbf{2} \rightarrow \mathbf{3} \rightarrow \mathbf{4} \rightarrow \mathbf{5}$ may occur to afford derivatives of a new heterocyclic system of pyrazolo[4,3-e][1,2,4]triazolo[1,5-c]pyrimidine 5 . Indeed, it has been shown that the imidoesters 2 react with hydrazides under prolonged reflux in bromobenzene to give compounds 5 in about $50 \%$ yield. The reaction mechanism illustrated in

\footnotetext{
${ }^{1}$ A preliminary communication on this transformation has been made in the form of the conference report. ${ }^{12}$
} 
Scheme 1 has been confirmed by isolation of the intermediates $3 \mathbf{a}$ and $4 \mathbf{a}$ in the reaction of imidoester $2(\mathrm{R}=\mathrm{H})$ with 4-methoxybenzoic acid hydrazide under milder conditions. Subsequent heating of a bromobenzene solution of pyrazolopyrimidine 4a smoothly converts it to the final product $\mathbf{5 a}$.
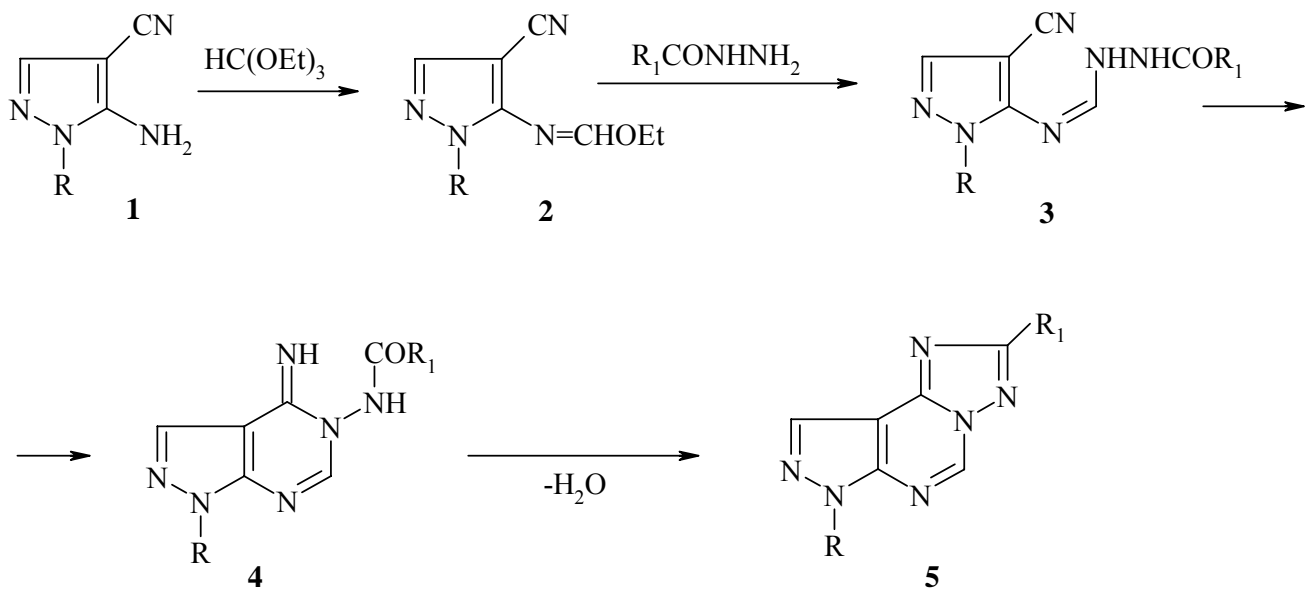
a) $\mathrm{R}=\mathrm{H}, \mathrm{R}_{1}=4-\mathrm{MeOC}_{6} \mathrm{H}_{4}$
f) $\mathrm{R}=\mathrm{Ph}, \mathrm{R}_{1}=4-\mathrm{MeOC}_{6} \mathrm{H}_{4}$
b) $\mathrm{R}=\mathrm{Me}, \mathrm{R}_{1}=\mathrm{Ph}$
g) $\mathrm{R}=\mathrm{Ph}, \mathrm{R}_{1}=4-\mathrm{ClC}_{6} \mathrm{H}_{4} \mathrm{OCH}_{2}$
c) $\mathrm{R}=\mathrm{Me}, \mathrm{R}_{1}=4-\mathrm{MeOC}_{6} \mathrm{H}_{4}$
h) $\mathrm{R}=4-\mathrm{MeC}_{6} \mathrm{H}_{4}, \mathrm{R}_{1}=\mathrm{Ph}$
d) $\mathrm{R}=\mathrm{PhCH}_{2}, \mathrm{R}_{1}=\mathrm{Ph}$
i) $\mathrm{R}=4-\mathrm{MeC}_{6} \mathrm{H}_{4}, \mathrm{R}_{1}=4-\mathrm{MeC}_{6} \mathrm{H}_{4}$
e) $\mathrm{R}=\mathrm{PhCH}_{2}, \mathrm{R}_{1}=4-\mathrm{MeOC}_{6} \mathrm{H}_{4}$

\section{Scheme 1}

\section{Results and Discussion}

The amidrazone 3a is obtained by short-term reflux of an ethanolic solution of the imidoester 2 $(\mathrm{R}=\mathrm{H})$ and 4-methoxybenzoylhydrazine taken in equimolar amounts. The IR-spectrum of 3a contains the bands characteristic of the stretching vibrations of nitrile $\left(2200 \mathrm{~cm}^{-1}\right)$, carbonyl $\left(1675 \mathrm{~cm}^{-1}\right)$, amidine $\left(1650 \mathrm{~cm}^{-1}\right)$ and imino $\left(3060,3330,3355 \mathrm{~cm}^{-1}\right)$ groups. Both the initial molecular ion peak $\mathrm{M}_{1}^{+}$(284) and that of the ion $\mathrm{M}_{2}^{+}$(266) related to the pyrazolotriazolopyrimidine $\mathbf{5 a}$ formed by elimination of a molecule of water from $\mathbf{3 a}$ in the gas phase appear in the mass spectrum of the amidrazone 3a. Heating a dimethylformamide solution of the amidrazone 3a gives rise to 4-iminopyrazolopyrimidine 4a, the IR-spectrum of which does not contain a $v_{\mathrm{CN}}$ vibration band, whereas $v_{\mathrm{CO}}$ and $v_{\mathrm{NH}}$ vibration bands appear at 1650 and 3115 , $3200 \mathrm{~cm}^{-1}$, respectively. The cyclization of $\mathbf{4 a}$ to $\mathbf{5 a}$, via elimination of a molecule of water, proceeds upon reflux in bromobenzene for 3-4 hours. The structure of pyrazolotriazolopyrimidine 5a was supported by its ${ }^{1} \mathrm{H}$ NMR spectrum that contained signals for a methoxy substituent $(3.85 \mathrm{ppm})$, two doublets (AB-quartet $J 8,7 \mathrm{~Hz}$ ) for aryl protons $(7.1$ and 
$8.2 \mathrm{ppm})$ and a sharp singlet $(9.5 \mathrm{ppm})$ for the $\mathrm{H}_{5}$ proton in the pyrimidine ring. At room temperature, the signals (8.6 and $\left.14.4 \mathrm{ppm}, \mathrm{DMSO}-d_{6}\right)$ of, respectively, $\mathrm{CH}$ and $\mathrm{NH}$ protons of the pyrazole ring, are substantially broadened, which is due to the fast prototropic exchange process associated with migration of a $\mathrm{NH}$ proton between the two nitrogen atoms.

With the goal of the synthesis of derivatives of another heterocyclic system of pyrazolo[4,3-e][1,2,4]triazolo[4,3-c]pyrimidine 8 isomeric to 5 we have prepared a series of 4acylhydrazinopyrazolo[3,4-d]pyrimidines 7 by coupling 6-chloropyrazolo[3,4-d]pyrimidines $\mathbf{6}^{3,4}$ with acylhydrazines and studying their cyclization reactions. The energy preference of the amino form of the acylhydrazines 7 over the possible imino tautomer is confirmed by their ${ }^{1} \mathrm{H}$ NMR spectra (DMSO- $d_{6}, 20^{\circ} \mathrm{C}$ ) which exhibit broadened AB quartet signals for the vicinal NH protons appearing at $9.5-11.0 \mathrm{ppm}$. Dehydration of the acylhydrazines 7 occurs under severe conditions on heating their melts and gives rise not to the expected pyrazolo[4,3-e]-[1,2,4]triazolo[4,3$c]$ pyrimidines 8, but to the isomeric pyrazolo[4,3-e][1,2,4]triazolo[1,5-c]-pyrimidines 5 (Scheme 2 ). The identity of the products of the dehydration of acylhydrazines 7 with those obtained by cyclization of the intermediate imines 4 was confirmed by comparison of their IR and ${ }^{1} \mathrm{H}$ NMR spectra.

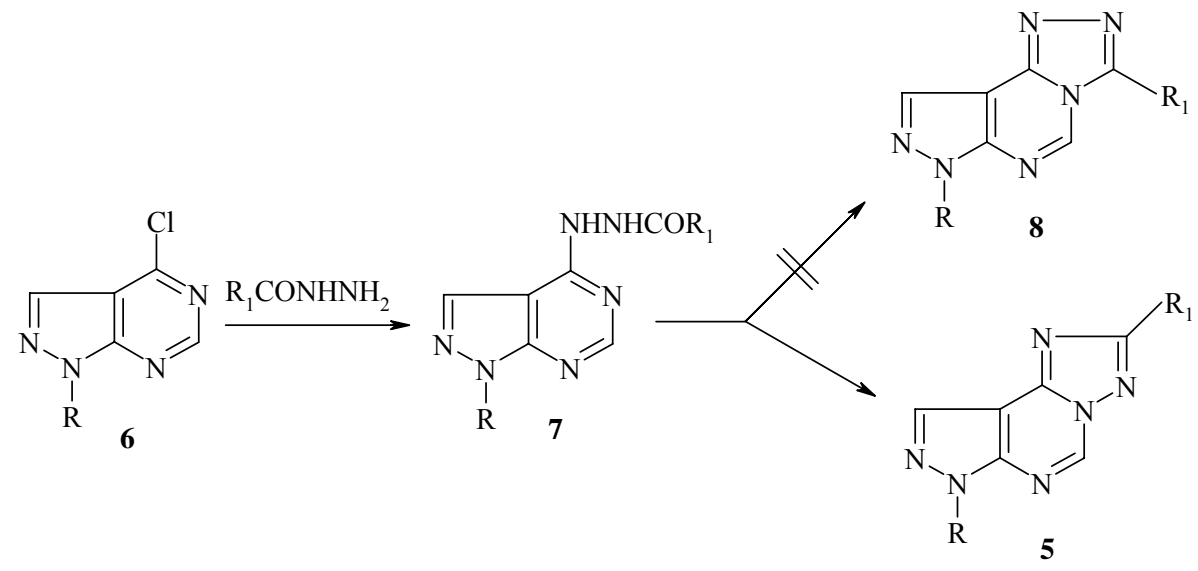

\section{Scheme 2}

The decisive evidence for the pyrazolo[4,3-e][1,2,4]triazolo[1,5-c]pyrimidine structure 5 of the compounds prepared by dehydration of the acylhydrazines 7 is provided by an X-ray determination of the molecular and crystal structure of compound $5 \mathrm{~g}$ obtained from $\mathbf{7 g}$ (Figure 1). 


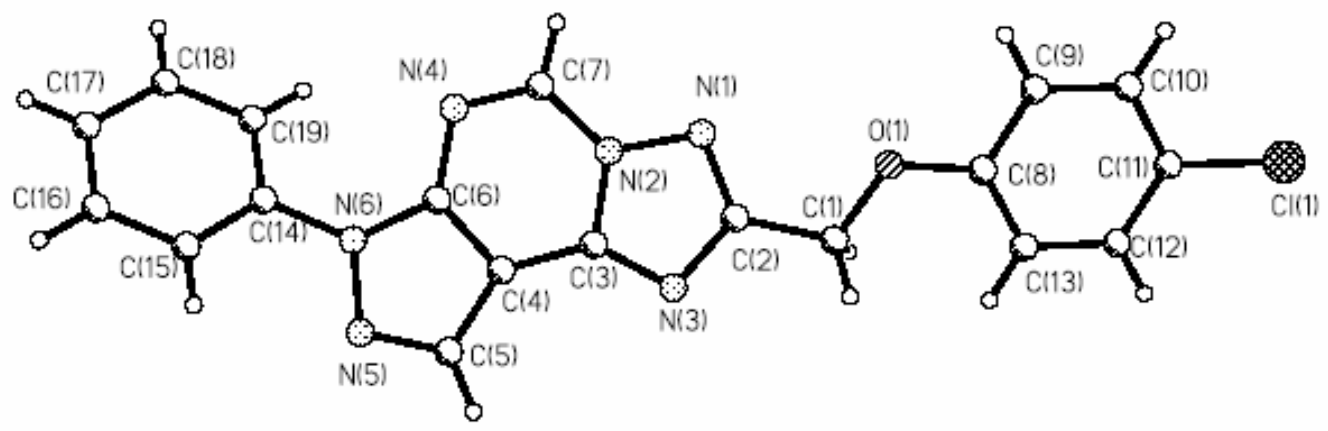

Figure 1. Perspective view and atom labeling of the X-ray crystal structure of $\mathbf{5 g}$.

The bond lengths in the tricyclic system are the following: $\mathrm{C}(2)-\mathrm{N}(2)$ 1.318, $\mathrm{C}(3)-\mathrm{N}(3)$ 1.322, $\mathrm{C}(5)-\mathrm{N}(5)$ 1.324, C(7)-N(4) $1.301 \AA), \mathrm{C}(2)-\mathrm{N}(3)$ 1.360, C(3)-N(2) 1.375, C(6)-N(4) 1.362, C(6)$\mathrm{N}(6)$ 1.361, $\mathrm{C}(7)-\mathrm{N}(2) 1.375 \AA$. The dihedral angles $\mathrm{C}(6) \mathrm{N}(6)-\mathrm{C}(14) \mathrm{C}(19)$ and $\mathrm{C}(1) \mathrm{O}(1)-$ $\mathrm{C}(8) \mathrm{C}(13)$ are $34.9^{\circ}$ and $20.6^{\circ}$, respectively.

Of certain interest is the mode of crystal packing for compound $5 \mathrm{~g}$. Due to the formation of a network of $\mathrm{C}-\mathrm{HN}$ bonds, the molecules of $\mathbf{5 g}$ are assembled in the crystal in almost planar layers. The attractive $\pi-\pi$ stacking interaction between the neighboring layers of the tricyclic aromatic systems of $\mathbf{5 g}$ is manifested by their almost parallel (the dihedral angle between the planes is $5.5^{\circ}$ ) orientation (Figures 2 and 3 ).

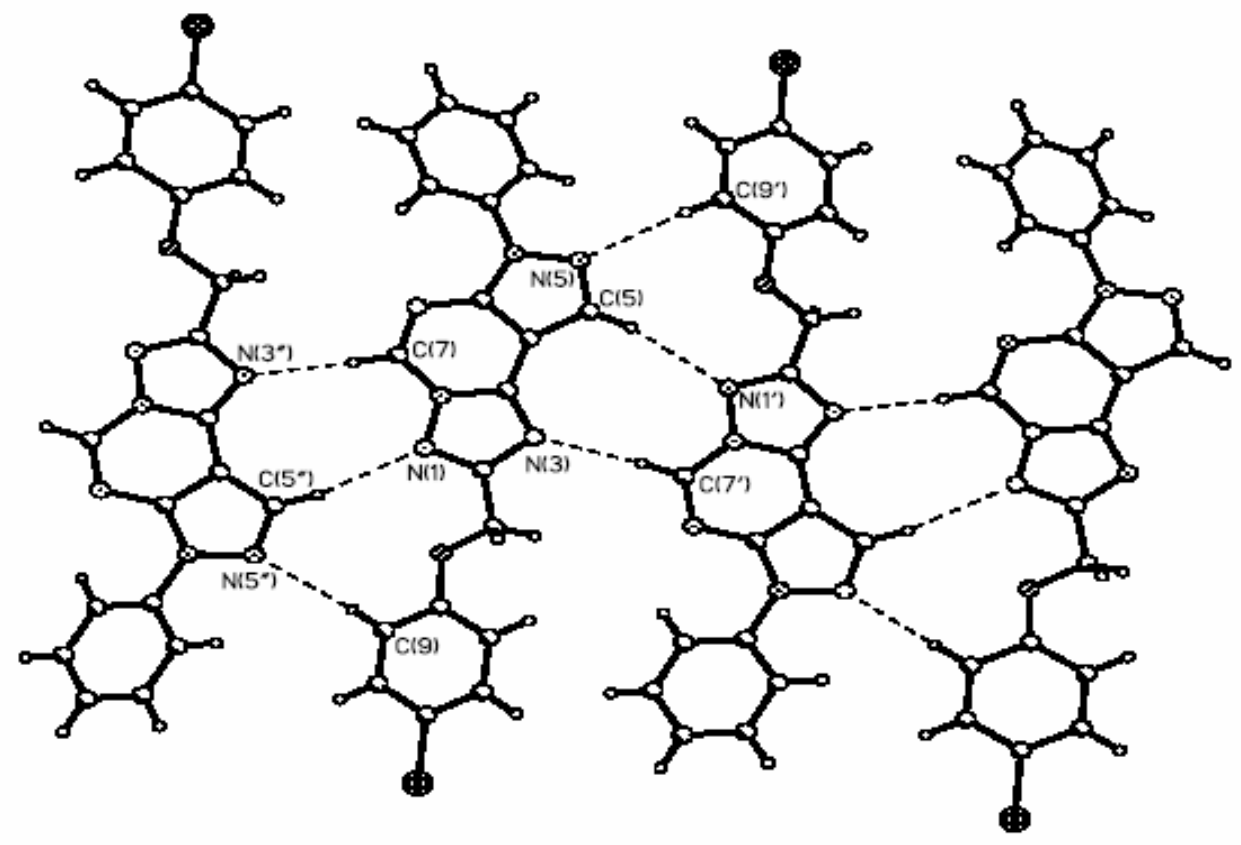

Figure 2. The layered crystal packing of molecules $5 g$. The N...H distances in the C-H...N hydrogen bridges are 2.54, 2.29 and $2.55 \AA$ for $\mathrm{N}(1) \ldots \mathrm{H}(5)-\mathrm{C}(5), \mathrm{N}(3) \ldots \mathrm{H}(3)-\mathrm{C}(7)$ and $\mathrm{N}(5) \mathrm{H}(9)-\mathrm{C}(9)$, respectively. 


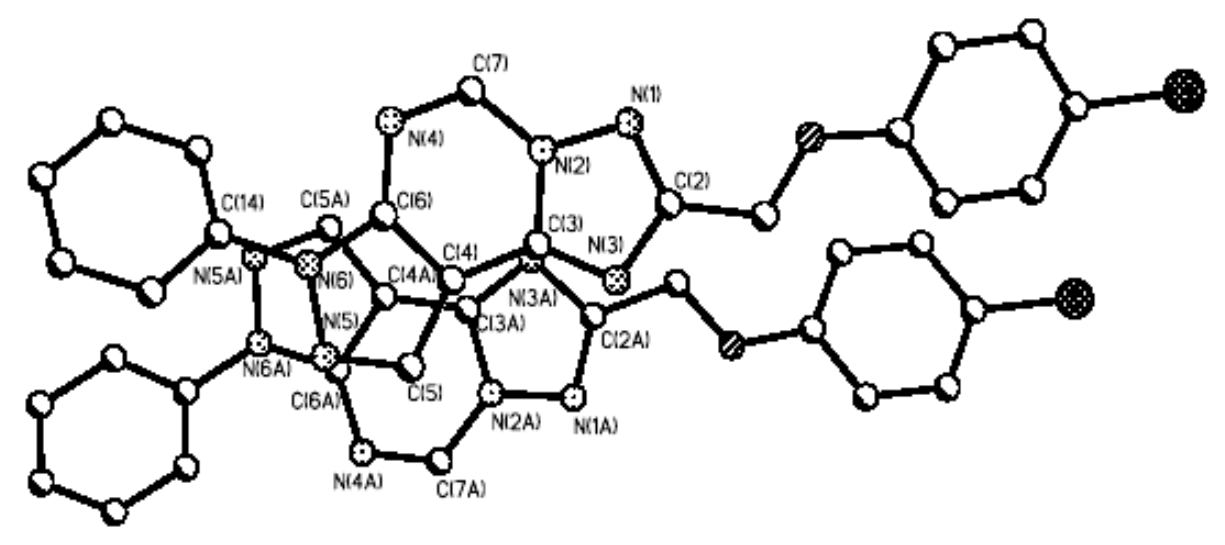

Figure 3. A fragment of the crystal structure of compound 5g. The shortest distance between the nearly parallel layers of the molecules is that between the $\mathrm{N}(5)$ and $\mathrm{C}(6)$ atoms of the fivemembered heterocyclic moiety.

\section{Conclusions}

Two new routes to the preparation of derivatives of a new fused heterocyclic system of pyrazolo[4,3-e][1,2,4]triazolo[1,5-c]pyrimidine 5 have been elaborated. The heterocyclization of the acylhydrazines $\mathbf{7}$ involves a rearrangement $\mathbf{7} \rightarrow \mathbf{5}$, the direction of which is opposite to that of the base-catalyzed Dimroth rearrangement. ${ }^{1}$ It is suggested here that the initial step of the $\mathbf{7} \rightarrow \mathbf{5}$ rearrangement involves tandem migration of hydride and an acyl group $(\mathbf{B} \rightarrow \mathbf{C})$. The 1-acyl-1hetarylhydrazine (C) undergoes cleavage of the N-N bond with the intermediate formation of the tight ionic pair (D) of the resonance-stabilized anion and the aminium cation, which then quenches to the $\mathrm{N}$-amine $\mathbf{E}$. The mechanism of the last stage is similar to that operating in the $\mathrm{N}$ amination of nitrogen heterocycles with hydroxylaminosulfuric $\operatorname{acid}^{14}$. The subsequent dehydration of $\mathbf{E}$ affords the final product (Scheme 3).

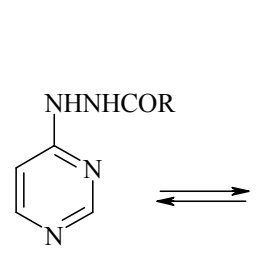

A

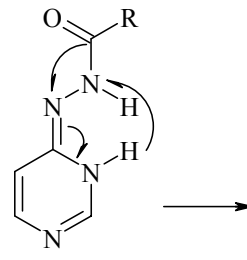<smiles>[R]C(=O)N=c1ccncn1N</smiles>

E
B

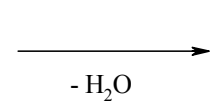

$-\mathrm{H}_{2} \mathrm{O}$<smiles>[R]C(=O)N(N)c1ccncn1</smiles>

C<smiles></smiles>

D

\section{Scheme 3}




\section{Experimental Section}

General Procedures. NMR spectra were recorded on a Varian Unity-300 spectrometer (300 $\mathrm{MHz}$ ) using DMSO and $\mathrm{CDCl}_{3}$ as solvents. IR spectra were recorded on a Specord 71 spectrophotometer in nujol or $\mathrm{KBr}$ tablets. Mass spectra were obtained on a Kratos instrument using an ionization energy of $71 \mathrm{eV}$ and a directing voltage of $1.75 \mathrm{kV}$. Single-crystal X-ray diffraction experiments were carried out with a Bruker SMART $1000 \mathrm{CCD}$ area detector using graphite monochromated Mo-K $\alpha$ radiation $(\lambda=0.71073 \AA), \omega$-scans with a $0.3^{\circ}$ step in $w$ and 10 s per frame exposure, $2 \theta<58^{\circ}$ ) at $120 \mathrm{~K}$. A total of 12416 reflections were measured, 4436 $\left(\mathrm{R}_{\text {int }}=0.0531\right)$. The structures were solved by direct method and refined by the full-matrix leastsquares against $F^{2}$ in anisotropic (for no-hydrogen atoms) approximation. The hydrogen atom positions were calculated and were refined isotropically in riding model approximation. The final refinements were converged to R1 $=0.0576$ (from 3549 unique reflections with $I>2 \sigma(I)$ ) and $\mathrm{wR} 2=0.1693$ (from all 4436 unique reflections; the number of the refined parameters is 244 . All calculations were performed on an IBM PC/AT using the SHELXTL software ${ }^{13}$. Crystal data for $5 \mathrm{~g}$. Colorless plate $\mathrm{C}_{19} \mathrm{H}_{13} \mathrm{ClN}_{6} \mathrm{O}(\mathrm{M}=376.80)$, monoclinic, space group $P 2_{1} / \mathrm{c}$ (no. 14), $a=19.047(7) \AA, b=12.206(5) \AA, c=7.226(3) \AA, \beta=93.292(8)^{\circ}, V=1677(1) \AA^{3}, \mathrm{Z}=4$, $d_{\text {calc }}=1.492 \mathrm{~g} \mathrm{~cm}^{-3}, \mu=0.252 \mathrm{~mm}^{-1}, \mathrm{~F}(000)=$, crystal size $0.07 \times 0.40 \times 0.50 \mathrm{~mm}$.

5-Amino-1H-pyrazole-4-carbonitriles (1) were prepared by coupling ethoxymethylenemalodinitrile with hydrazine hydrate and the corresponding monosubstituted hydrazines according to the previously described procedure. ${ }^{4}$ By treatment of 5-amino- $1 H$-pyrazole-4carbonitriles 1 with ethyl orthoformate, imidoesters 2 were prepared following a literature method. ${ }^{2}$ Chloropyrazolopyrimidines 6 were obtained by the method described by Robins., ${ }^{3,4}$

5-[2-(4-methoxyphenyl)-1-hydrazinomethylidenamino]-1H-4-pyrazolecarbonitrile (3a). To a solution of imidoester $2 \mathrm{a}(0.082 \mathrm{~g}, 0.5 \mathrm{mmol})$ in $2 \mathrm{ml}$ of ethanol a solution 4-methoxybenzoyl hydrazine $(0.083 \mathrm{~g}, 0.5 \mathrm{mmol})$ in $1 \mathrm{ml}$ of ethanol was added and the reaction mixture was allowed to stand at room temperature for $1 \mathrm{~h}$. The precipitate formed was filtered off, washed with ethanol and water and dried $(0.060$ g, $0.21 \mathrm{mmol}, 42.3 \%)$ : m.p. $304-306{ }^{\circ} \mathrm{C}$, molecular ion $\mathrm{m} / \mathrm{e}$ 284; IR $\left(\mathrm{v}, \mathrm{cm}^{-1}\right): 3555,3330,3060,2200,1673,1650$. Anal. Calcd. for $\mathrm{C}_{13} \mathrm{H}_{12} \mathrm{~N}_{6} \mathrm{O}_{2}: \mathrm{C}$, 54.92; H, 4.23; N, 29.58. Found: C, 54.71; H, 4.35; N, 29.63.

\section{4-Amino-5-(4-methoxyphenylcarboxamido)-4,5-dihydro-1 $\mathrm{H}$-pyrazolo[3,4-d]pyrimidine}

(4a). A suspension of carbonitrile 3a $(0.060 \mathrm{~g}, 0.21 \mathrm{mmol})$ in $2 \mathrm{ml}$ of DMF was heated to reflux for $10 \mathrm{~min}$. The precipitate formed was filtered off, washed with hexane and dried $(0.050 \mathrm{~g}$, 0.17 mmol, $92 \%)$ : m.p. $345-346{ }^{\circ} \mathrm{C}$; IR $\left(v, \mathrm{~cm}^{-1}\right): 3200,3115$, 1650. Anal. Calcd. for $\mathrm{C}_{13} \mathrm{H}_{12} \mathrm{~N}_{6} \mathrm{O}_{2}$ : C, 54.92; H, 4.23; N, 29.58. Found: C, 55.12; H, 4.35; N, 29.71.

2-(4-Methoxyphenyl)-7H-pyrazolo[4,3-e]triazolo[1,5-c]pyrimidine (5a). A suspension of pyrimidine $4 \mathrm{a}(0.100 \mathrm{~g}, 0.35 \mathrm{mmol})$ in $2 \mathrm{ml}$ of bromobenzene was refluxed for $10 \mathrm{~h}$, then cooled to room temperature and the formed colorless precipitate was filtered off, washed with ethanol, and dried $(0.060$ g, $0.225 \mathrm{mmol}, 64 \%)$ : m. p. $274-275^{\circ} \mathrm{C}$; IR $\left(v, \mathrm{~cm}^{-1}\right): 3167,3100,1650 ;{ }^{1} \mathrm{H}$ 
NMR ( $\delta$, ppm, DMSO): $3.85(\mathrm{~s}, 3 \mathrm{H}), 7.1(\mathrm{~d}, 2 \mathrm{H}), 8.2(\mathrm{~d}, 2 \mathrm{H}), 8.6(\mathrm{~s}, 1 \mathrm{H}), 14,4(\mathrm{~s}, 1 \mathrm{H})$. Molecular ion m/e 266. Anal. Calcd. for $\mathrm{C}_{13} \mathrm{H}_{10} \mathrm{~N}_{6} \mathrm{O}$ : C, 58.65; H, 3.76; N, 31.58. Found: C, 58.78; H, 3.83; N, 31.46 .

General procedure for the preparation of 2,7-disubstituted $7 \mathrm{H}$-pyrazolo[4,3-e][1,2,3]triazolo[1,5-c]pyrimidine $7 \mathrm{~b}-\mathrm{i}$

A suspension of equimolar amounts of 1-substituted 4- chloro-pyrazolopyrimidines 6 and the corresponding acylhydrazine in ethanol was refluxed for $0.5-1.0 \mathrm{~h}$. On heating, the suspension passes into solution and a precipitate of 2,7- disubstituted 7H-pyrazolo[4,3-e][1,2,3]-triazolo[1,5c]pyrimidine $\mathbf{7 b - i}$ is gradually formed. It was filtered off, washed with ethanol and water and crystallized from DMF.

1-(1-Methyl-1H-pyrazolo[3,4-d]pyrimidin-4-yl)-2-(4-phenylcarboxamido)hydrazine (7b). Yield 69\%; m. p. $245-246{ }^{\circ} \mathrm{C} ;{ }^{1} \mathrm{H}$ NMR $\left(\delta\right.$, ppm, DMSO- $\left.d_{6}\right): 3.95(\mathrm{~s}, 1 \mathrm{H}), 7.4-8.2(\mathrm{~m}, 6 \mathrm{H}), 9.8$ - 11.0 (m, 2H). Anal. Calcd. for $\mathrm{C}_{13} \mathrm{H}_{12} \mathrm{~N}_{6} \mathrm{O}$ : C, 58.21; H, 4.48; N, 31.34. Found: C, 58.42; H, $4.54 ; \mathrm{N}, 31.26$.

1-(1-Methyl-1H-pyrazolo[3,4-d]pyrimidin-4-yl)-2-(4-methoxyphenylcarboxamido)hydrazine (7c). Yield 78\%, m. p. $228-230{ }^{\circ} \mathrm{C} ;{ }^{1} \mathrm{H}$ NMR ( $\delta$, ppm, DMSO- $d_{6}$ ): $3.80(\mathrm{~s}, 3 \mathrm{H}), 3.90(\mathrm{~s}, 3 \mathrm{H}), 7.0-8.5(\mathrm{~m}, 6 \mathrm{H})$, $11.0-11.2(\mathrm{~d}, 1 \mathrm{H}), 12.2(\mathrm{~s}, 1 \mathrm{H})$. Anal. Calc. for $\mathrm{C}_{14} \mathrm{H}_{14} \mathrm{~N}_{6} \mathrm{O}: \mathrm{C}, 56.37 ; \mathrm{H}, 4.70 ; \mathrm{N}, 28.19$. Found: C, $56.48 ; \mathrm{H}, 4.91 ; \mathrm{N}, 28.31$.

1-(1-Benzyl-1H-pyrazolo[3,4-d]pyrimidin-4-yl)-2-(4-phenylcarboxamido)hydrazine (7d). Yield 73\%; m. p. $230-232{ }^{\circ} \mathrm{C} ;{ }^{1} \mathrm{H}$ NMR ( $\delta$, ppm, DMSO- $\left.d_{6}\right): 5.50(\mathrm{~s}, 1 \mathrm{H}), 7.2-8.0(\mathrm{~m}, 10 \mathrm{H})$, $8.12(\mathrm{~s}, 1 \mathrm{H}), 8.38(\mathrm{~s}, 1 \mathrm{H}), 11.5(\mathrm{~d}, 1 \mathrm{H}), 12.5(\mathrm{~s}, 1 \mathrm{H})$. Anal. Calc. for $\mathrm{C}_{19} \mathrm{H}_{16} \mathrm{~N}_{6} \mathrm{O}: \mathrm{C}, 66.28 ; \mathrm{H}$, 4.65; N, 24.42. Found: C, 66.41; H, 4.72; N, 24.36.

1-(1-Benzyl-1H-pyrazolo[3,4-d]pyrimidin-4-yl)-2-(4-p-methoxyhenylcarboxamido)hydrazine ( 7e). Yield 73\%; m. p. $217-219{ }^{\circ} \mathrm{C} ;{ }^{1} \mathrm{H}$ NMR ( $\delta$, ppm, DMSO- $\left.d_{6}\right): 3.80(\mathrm{~s}, 3 \mathrm{H}), 5.6(\mathrm{~d}, 2 \mathrm{H})$, $7.1-8.5(\mathrm{~m}, 12 \mathrm{H}), 11.1(\mathrm{~s}, 1 \mathrm{H})$. Anal. Calcd. for $\mathrm{C}_{20} \mathrm{H}_{18} \mathrm{~N}_{6} \mathrm{O}_{2}: \mathrm{C}, 64.17 ; \mathrm{H}, 4.81 ; \mathrm{N}, 22.46$. Found: C, 64.53; H, 4.68; N, 22.72.

1-(1-Phenyl-1H-pyrazolo[3,4-d]pyrimidin-4-yl)-2-(4-methoxyphenylcarboxamido)hydrazine (7f). Yield 69\%; m. p. 233-235 ${ }^{\circ} \mathrm{C} ;{ }^{1} \mathrm{H}$ NMR ( $\delta$, ppm, DMSO- $\left.d_{6}\right): 3.90(\mathrm{~s}, 3 \mathrm{H}), 3.90(\mathrm{~s}, 3 \mathrm{H})$, $7.0-8.6(\mathrm{~m}, 11 \mathrm{H}), 9.8-11.6(\mathrm{~m}, 2 \mathrm{H})$. Anal. Calcd. for $\mathrm{C}_{19} \mathrm{H}_{16} \mathrm{~N}_{6} \mathrm{O}_{2}: \mathrm{C}, 63.34 ; \mathrm{H}, 4.45 ; \mathrm{N}$, 23.33. Found: C, 63.27; H, 4.51; N, 23.15.

1-(1-Phenyl-1H-pyrazolo[3,4-d]pyrimidin-4-yl)-2-(4-chlorophenyloxyacetylcarboxamido) hydrazine (7g). Yield 86\%; m. p. $218-220{ }^{\circ} \mathrm{C} ;{ }^{1} \mathrm{H}$ NMR ( $\delta$, ppm, DMSO- $\left.d_{6}\right): 5.50(\mathrm{~s}, 2 \mathrm{H}), 3.90$ $(\mathrm{s}, 3 \mathrm{H}), 7.0-8.6(\mathrm{~m}, 11 \mathrm{H}), 9.8-11.6(\mathrm{~m}, 2 \mathrm{H})$. Anal. Calcd. for $\mathrm{C}_{19} \mathrm{H}_{16} \mathrm{~N}_{6} \mathrm{O}_{2}$ : C, 63.34; $\mathrm{H}, 4.45$; N, 23.33. Found: C, 63.27; H, 4.51; N, 23.15.

1-[1-(4-Methylphenyl)-1H-pyrazolo[3,4-d]pyrimidin-4-yl]-2-(4-phenylcarboxamido)

hydrazine (7h). Yield 89 \%, M. p. $263-265{ }^{\circ} \mathrm{C} .{ }^{1} \mathrm{H}$ NMR $\left(\delta\right.$, ppm, DMSO- $\left.d_{6}\right): 2.50$ (s, 3H), 7.2 - $8.2(\mathrm{~m}, 11 \mathrm{H}), 10.0-11.1(\mathrm{~m}, 2 \mathrm{H})$. Anal. Calcd. for $\mathrm{C}_{19} \mathrm{H}_{16} \mathrm{~N}_{6} \mathrm{O}: \mathrm{C}, 66.28 ; \mathrm{H}, 4.65 ; \mathrm{N}, 24.42$. Found: C, 66.41; H, 4.70; N, 24.65.

1-[1-(4-Methylphenyl)-1H-pyrazolo[3,4-d]pyrimidin-4-yl]-2-[4-(4-methylphenyl) 
carboxamido] hydrazine (7i). Yield $89 \%$, M. p. $263-265{ }^{\circ} \mathrm{C} .{ }^{1} \mathrm{H}$ NMR ( $\delta$, ppm, DMSO- $\left.d_{6}\right)$ : $2.50(\mathrm{~s}, 3 \mathrm{H}), 7.2-8.2(\mathrm{~m}, 11 \mathrm{H}), 10.0-11.1(\mathrm{~m}, 2 \mathrm{H})$. Anal. Calc. for $\mathrm{C}_{19} \mathrm{H}_{16} \mathrm{~N}_{6} \mathrm{O}: \mathrm{C}, 66.28 ; \mathrm{H}$, 4.65; N, 24.42. Found: C, 66.41; H, 4.70; N, 24.65.

General procedure for the preparation of 2,7-disubstituted-7H-pyrazolo[4,3$e][1,2,4]$ triazolo[1,5-c]pyrimidines $5 b-i$

Method (a). A bromobenzene solution of equimolar amounts of imidoester 2 ( $\mathrm{R}=\mathrm{Me}, \mathrm{CH}_{2} \mathrm{Ph}$, $\mathrm{Ph}, \mathrm{C}_{6} \mathrm{H}_{4} \mathrm{Me}-p$ ) and the corresponding acylhydrazine was refluxed for $5-10 \mathrm{~h}$, allowed to reach room temperature and the precipitate formed was filtered off, washed with ethanol, dried and crystallized from DMF.

Method (b). 4-Acylhydrazino derivatives of pyrazolo[3,4-d]pyrimidines 7b-i were melted in an open vessel until evaporation of the eliminated water ceased. The remaining solid was crystallized from DMF. The melting points and yields of compounds 5a-i obtained by the methods (a) and (b) are given in Table $\mathbf{1}$.

Table 1. Melting points and yields of derivatives of $7 H$-pyrazolo[4,3-e][1,2,4]triazolo[1,5-c]pyrimidine 5 synthesized by the methods (a) and (b)

\begin{tabular}{llll}
\hline Compound & M. p., ${ }^{\circ} \mathrm{C}$ & Yield by method (a) & Yield by method (b) \\
\hline $\mathbf{5 a}$ & $274-275$ & 64 & - \\
$\mathbf{5 b}$ & $247-249$ & 45 & 75 \\
$\mathbf{5 c}$ & $242-243$ & 39 & 65 \\
$\mathbf{5 d}$ & $278-280$ & 42 & 65 \\
$\mathbf{5 e}$ & $208-209$ & 54 & 76 \\
$\mathbf{5 f}$ & $233-235$ & 43 & 72 \\
$\mathbf{5 g}$ & $190-192$ & 58 & 70 \\
$\mathbf{5 h}$ & $282-283$ & 38 & 66 \\
$\mathbf{5 i}$ & $310-311$ & 56 & 71 \\
\hline
\end{tabular}

2-Phenyl-7-methyl-7H-pyrazolo[4,3-e $][1,2,4]$ triazolo[1,5-c]pyrimidine (5b). ${ }^{1} \mathrm{H}$ NMR $(\delta$, ppm, DMSO- $\left.d_{6}\right): 4.20(\mathrm{~s}, 3 \mathrm{H}), 7.5-8.3(\mathrm{~m}, 5 \mathrm{H}), 8.40(\mathrm{~s}, 1 \mathrm{H})$. Anal. Calc. for $\mathrm{C}_{13} \mathrm{H}_{10} \mathrm{~N}_{6}$ : C, 62.40; H, 4.01; N, 33.60 Found: C, 62.30; H, 4.00; N, 33.75

2-(4-Methoxyphenyl-7-methyl-7H-pyrazolo[4,3-e][1,2,4]triazolo[1,5-c]pyrimidine (5c). ${ }^{1} \mathrm{H}$ NMR ( $\delta$, ppm, DMSO-d $\left.d_{6}\right): 3.9$ (s, 3H), 4.2 (s, 3H), $7.0-8.0(\mathrm{~m}, 4 \mathrm{H}), 8.40(\mathrm{~s}, 1 \mathrm{H}), 9.1$ (s, 1H). Anal. Calc. for $\mathrm{C}_{14} \mathrm{H}_{12} \mathrm{~N}_{6} \mathrm{O}$ : C, 60.04; H, 4.30; N, 30.00. Found: C, 60.30; H, 4.10; N, 29.91. 2-Phenyl-7-benzyl-7H-pyrazolo[4,3-e $][1,2,4]$ triazolo[1,5-c]pyrimidine (5d). NMR ${ }^{1} \mathrm{H} \quad(\delta$, ppm, DMSO-d $\left.d_{6}\right): 5.70(\mathrm{~s}, 2 \mathrm{H}), 7.3-8.3(\mathrm{~m}, 10 \mathrm{H}), 8.40(\mathrm{~s}, 1 \mathrm{H}), 9.11(\mathrm{~s}, 1 \mathrm{H})$. Anal. Calc. for $\mathrm{C}_{19} \mathrm{H}_{14} \mathrm{~N}_{6}$ : C, 69.94; H, 4.30; N, 25.77 Found: C, 69.50; H, 4.15; N, 25.80.

2-(4-Methoxyphenyl-7-benzyl-7H-pyrazolo[4,3-e][1,2,4]triazolo[1,5-c]pyrimidine (5e).

${ }^{1} \mathrm{H}$ NMR ( $\delta$, ppm, DMSO-d $\left.d_{6}\right) 3.90$ (s, 3H), 5.70 (s, 2H), $7.0-7.4(\mathrm{~m}, 9 \mathrm{H}), 8.40(\mathrm{~s}, 1 \mathrm{H}), 9.20$ (s, 1H). Anal. Calc. for $\mathrm{C}_{20} \mathrm{H}_{16} \mathrm{~N}_{6} \mathrm{O}: \mathrm{C}, 67.42 ; \mathrm{H}, 4.49 ; \mathrm{N}, 23.60$. Found: $\mathrm{C}, 67.50 ; \mathrm{H}, 4.20 ; \mathrm{N}, 23.59$. 
2-(4-Methoxyphenyl-7-phenyl-7H-pyrazolo[4,3-e][1,2,4]triazolo[1,5-c]pyrimidine (5f).

${ }^{1} \mathrm{H}$ NMR $\left(\delta\right.$, ppm, DMSO-d $\left.d_{6}\right): 7.4-8.4(\mathrm{~m}, 12 \mathrm{H}), 8.60(\mathrm{~s}, 1 \mathrm{H}), 9.20(\mathrm{~s}, 1 \mathrm{H})$. Anal. Calc. for $\mathrm{C}_{19} \mathrm{H}_{14} \mathrm{~N}_{6} \mathrm{O}$ : C, 66.66; H, 4.03; N, 24.56. Found: C, 66.50; H, 4.10; N, 24.60.

2-(4-Chlorophenoxymethyl-7-phenyl-7H-pyrazolo[4,3-e][1,2,4]triazolo[1,5-c]

pyrimidine (5g). ${ }^{1} \mathrm{H}$ NMR $\left(\delta\right.$, ppm, DMSO- $\left.d_{6}\right): 5.4(\mathrm{~s}, 2 \mathrm{H}), 7.0-8.2(\mathrm{~m}, 9 \mathrm{H}), 8.50(\mathrm{~s}, 1 \mathrm{H}), 9.20$ (s, 1H). Anal. Calc. for $\mathrm{C}_{19} \mathrm{H}_{13} \mathrm{~N}_{6} \mathrm{OCl}$ : C, 60.56; H, 3.45; N, 22.31; Cl, 9.43. Found: $\mathrm{C}, 60.72 ; \mathrm{H}$, 3.56; N, 22.46; Cl, 9.62 .

2-Phenyl-7-(4-methylphenyl)-7H-pyrazolo[4,3-e][1,2,4]triazolo[1,5-c]pyrimidine (5h). ${ }^{1} \mathrm{H}$ $\operatorname{NMR}\left(\delta\right.$, ppm, DMSO- $\left.d_{6}\right): 2.40(\mathrm{~s}, 3 \mathrm{H}), 7.4-8.4(\mathrm{~m}, 9 \mathrm{H}), 8.60(\mathrm{~s}, 1 \mathrm{H}), 9.20(\mathrm{~s}, 1 \mathrm{H})$. Anal. Calc. for $\mathrm{C}_{19} \mathrm{H}_{14} \mathrm{~N}_{6}$ : C, 69.94; H, 4.30; N, 25.77 Found: C, 70.15; H, 4.16; N, 25.91.

2-(4-Methylphenyl)-7-(4-methylphenyl)-7H-pyrazolo[4,3-e][1,2,4]triazolo[1,5-c]pyrimidine (5i). ${ }^{1} \mathrm{H}$ NMR $\left(\delta\right.$, ppm, DMSO- $\left.d_{6}\right): 2.40(\mathrm{~s}, 6 \mathrm{H}), 7.3-8.2(\mathrm{~m}, 8 \mathrm{H}), 8.60(\mathrm{~s}, 1 \mathrm{H}), 9.20(\mathrm{~s}, 1 \mathrm{H})$. Anal. Calc. for $\mathrm{C}_{20} \mathrm{H}_{16} \mathrm{~N}_{6}$ : C, 70.59; H, 4.71; N, 24.71 Found: C, 70.72; H, 4.83; N, 24.93.

\section{Acknowledgments}

This work was supported by Grants N. Sh. 945. 03. 2003 from Ministry of Education and Science RF and REC-004 from CRDF and Ministry of Education and Science RF.

\section{References}

1. Taylor, E. C.; Mc Killop, A. The Chemistry of Cyclic Enaminonitriles and o-Aminonitriles in Adv. in Org. Chem., J. Wiley-Interscience: New York, 1970; Vol. 7, p 415.

2. Taylor, E. C.; Loeffler, R. K. J. Am. Chem. Soc. 1960, 82, 3147.

3. Robins, R. K. J. Am. Chem. Soc. 1956, 78, 784.

4. Cheng, C. C.; Robins, R. K. J. Org. Chem.1956, 21, 1240.

5. Cheng, C. C.; Robins, R. K. J. Org. Chem. 1958, 23, 191.

6. Cheng, C. C.; Robins, R. K. J. Org. Chem. 1958, 23, 852

7. Bhat, G. A.; Montero, J. G.; Panzica, R. P.; Warting, L. L.; Towsend, L. B. J. Med. Chem. 1981, 24, 1165.

8. Petrie, C. R.; Cottam, H. B.; Mc Kernan, P. A.; Robins, R. K.; Revankar, G. R. J. Med. Chem. 1985, 28, 1010.

9. Avila, J. L.; Polegre, M. A.; Avila, A. R.; Robins, R. K. Comp. Biochem. Physiol. 1986, 83 C, 285.

10. Anderson, J. D.; Cottam, H. B.; Larson, S. B.; Nord, L. D.; Revankar, G. R.; Robins, R. K. J. He terocycl. Chem. 1990, 27, 439.

11. Zaharie, C. B.; Connolly, T. P.; Rej, R.; Attardo, G.; Penney, C. L. Tetrahedron 1996, 52, 2271.

12. Krasnikov, V. V.; Milgizina, G. R.; Tyurin, R. V.; Minyaeva, L. G.; Mezheritskii, V. V. In: Abstracts of reports at the $1^{\text {st }}$ International Conference "Chemistry and Biological Activity of NitrogenContaining Heterocycles and Alkaloids" Moscow, 2001; Vol. 1, p 356.

13. Sheldrick, G. M. SHELXTL-97, Version 5.10, Bruker AXS Inc., Madison, WI-53719, USA.

14. Rees, C. W.; Storr, R. C. Chem. Commun. 1965, 193. 